Heteroatom Chemistry

Volume 1, Number 2, 1990

\title{
1-Phosphinodiazaphosphene: Synthesis, Crystal Structure, and Bonding Properties
}

\author{
Oliver Altmeyer, Edgar Niecke," and Martin Nieger \\ Anorganisch-Chemisches Institut der Universität, Gerhard-Domagk-Str. 1, D-5300 Bonn 1, \\ Federal Republic of Germany \\ Thilo Busch and Wolfgang W. Schoeller \\ Fakultät für Chemie der Universität, Postfach 8640, D-4800 Bielefeld 1, \\ Federal Republic of Germany \\ Dietmar Stalke
} Anorganisch-Chemisches Institut der Universität, Tammannstraße 4, D-5300 Göttingen,
Federal Republic of Germany

Received 6 October 1989.

Dedicated to Professor Alfred Schmidpeter on the occasion of his 60th birthday.

\begin{abstract}
The iminophosphane, $\quad t B u_{2} P-P=N-N R_{2}$ $\left(R=\mathrm{SiMe}_{3}\right)$, produced by base-catalyzed elimination of ClSiMe $e_{3}$ from the corresponding phosphane, possesses an unusually long $P N$ bond (162 pm), which is in accord with quantum chemical calculations.
\end{abstract}

According to quantum chemical calculations $\sigma$ electron-push-pull substitution exerts unexpected bonding effects on P(III) double bonded systems [1]; in iminophosphanes a strong $\sigma$-acceptor at phosphorus tends to shorten the PN double bond (case I) with concomitant linearization of the nitrogen environment, while a $\sigma$-acceptor at the nitrogen does the opposite; it lengthens the PN bond (case II). Hitherto only case I has been experimentally verified in detail [2] (Scheme 1). Here we report on the synthesis, structural elucidation, and quantum chemical investigations on its bonding properties of a novel 1-phosphinodiazaphosphene (3).

\footnotetext{
* To whom correspondence should be addressed.
}

Reaction of the hydrazino(dichloro)phosphane 1 [3] with one equivalent of lithium-bis-t.butylphosphide [4] produces the hydrazino-diphosphane 2. Treatment of 2 with DBU results in a smooth elimination of chlorosilane with formation of the 1-phosphinodiazaphosphene 3 (Scheme 2). The constitution of both compounds was proven by means of mass and NMR spectral data, and X-ray structural analysis for 3 . The deshielding of the low field ${ }^{31} \mathrm{P}$ signal of the AX spectrum of $3(\delta=429)$ is consistent with the formation of the PN-double bond system. The structure of $\mathbf{3}$ is illustrated in Figure 1. In contrast to 1-aminodiazaphosphene, tmp- $\mathrm{P}=\mathrm{N}-\mathrm{N}\left(\mathrm{SiMe}_{3}\right)_{2} \quad 4$ [5], in 3 the bis (trimethylsilyl)amino group is coplanar with the central $\mathrm{P}_{\pi}$-system, thus allowing the formation of a 4-electron 3-center-(PNN) $\mathrm{p}_{\pi}$-system (III, Scheme 3). This is further corroborated by the shortening of the $\mathrm{N}-\mathrm{N}$ bond, $138 \mathrm{pm}$, and the widening of the $\mathrm{P}-\mathrm{N}-\mathrm{N}$ angle, $124^{\circ}$, compared to $4,150 \mathrm{pm}, 107^{\circ}$ [5]. The P-P bond distance, $220 \mathrm{pm}$, is in accord with the order of unity, while the valence angle at the $\sigma^{2}$-phosphorus, $95^{\circ}$, is the smallest found so far in iminophosphanes [6]. However, most remarkable is the unusually long PN double bond distance, $162 \mathrm{pm}$, which is even longer than found in bis(amino)phosphenium cations [7].

$1042-7163 / 90 / \$ 3.50+.25$ 
<smiles></smiles>

I II
This fact will now be rationalized on the basis of quantum chemical calculations. Various model geometries were probed by energy optimized ab initio calculations [8] (Table 1). In accord with previous considerations [1b] an amino group at nitrogen lengthens the PN double bond, at times in reference to the parent iminophosphane. The phosphino group at phosphorus itself exerts only negligible changes on the PN bond. In the notation of the previous model [1b] of substituent effects, the phosphino group (at $\mathrm{P}$ ) acts as a $\sigma$-donor and the amino group (at $\mathrm{N}$ ) simultaneously as a $\sigma$-acceptor and a $\pi$-donor. Consequently both substituents at the PN double bond refer to the case of $\sigma$-push pull substitution and enforce enhanced lengthening of the PN double bond. If this is indeed the case, the calculations reveal the PN bond $(159 \mathrm{pm})$ to be much longer than for the mono-substituted compounds (see Table 1). Further analysis of its electron contribution (not recorded in detail) on the parent 1-phosphinodiazaphosphene indicates a build-up of negative charge at the double bonded phosphorus.

This is in accord with the canonical structure III. Concomitantly, the amino group at nitrogen is strongly conjugating with the PN double bond (Scheme 3).

The case at hand may be compared with structural findings on 4 [5]. There, the PN double bond is also very long ( $160 \mathrm{pm}$ [5]), but the bis-silylaminogroup (at $\mathrm{N}$ ) is orthogonal to the central $\pi$-system [9]. Thus, it is incapable of allylic resonance. In addition the valence angle at the double bonded nitrogen is almost tetrahedral $\left(107^{\circ}\right)$. Consequently this structure may best be described by canonical structure IV. Thus, 3 and 4 both possess extremely long PN double bonds, with varying polarization of the central $\pi$ bond.

\section{EXPERIMENTAL}

The reactions were performed under argon. The solvents were dried and purified by standard methods. Mass spectra were recorded on a VG 12-250 at $70 \mathrm{eV}$ under electronic impact. Nuclear magnetic resonance spectra were recorded on a multinuclear spectrometer at $90\left({ }^{1} \mathrm{H}\right), 22.63\left({ }^{13} \mathrm{C}\right)$ and $32.20 \mathrm{MHz}$ ( $\left.{ }^{31} \mathrm{P}\right)$ with TMS as internal $\left({ }^{1} \mathrm{H},{ }^{13} \mathrm{C}\right)$ and $85 \% \mathrm{H}_{3} \mathrm{PO}_{4}$ $\left.{ }^{31} \mathrm{P}\right)$ as external standard.

\section{Preparation of $t B u_{2} P-P(C l) N(R) N R_{2}$ (2)}

To a solution of $5.0 \mathrm{~g}(14.3 \mathrm{mmol}) \mathrm{R}_{2} \mathrm{~N}(\mathrm{R}) \mathrm{NPCl}_{2}$

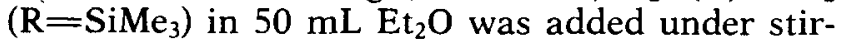
ring at $-40^{\circ} \mathrm{C} 2.17 \mathrm{~g}(14.3 \mathrm{mmol})$ of $\mathrm{tBu}_{2} \mathrm{PLi}$ in 20

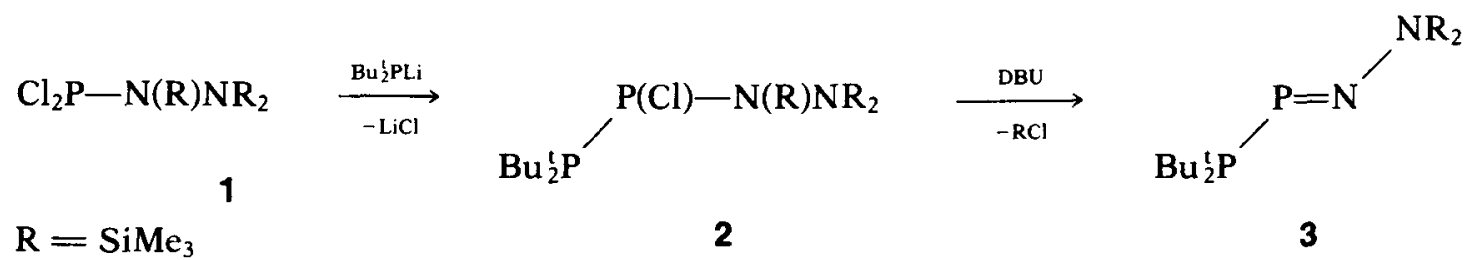

SCHEME 2
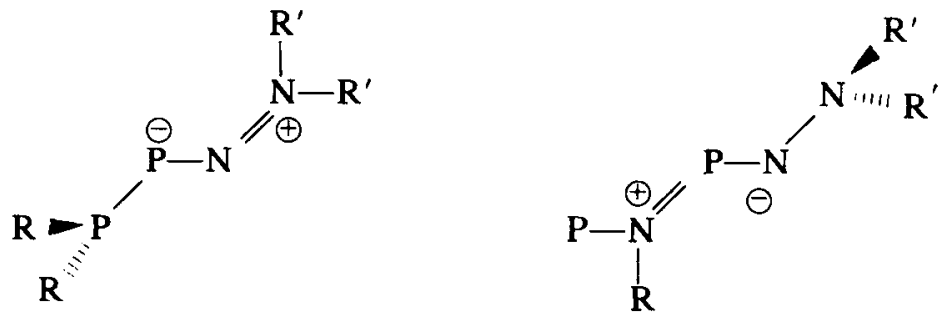

III

IV

3: $\mathrm{R}=\mathrm{tBu} ; \mathrm{R}^{\prime}=\mathrm{SiMe}_{3}$

4: $\mathrm{RR}=2,2,6,6-\mathrm{Me}_{4} \mathrm{C}_{5} \mathrm{H}_{6} ; \mathrm{R}^{\prime}=\mathrm{SiMe}_{3}$

\section{SCHEME 3}




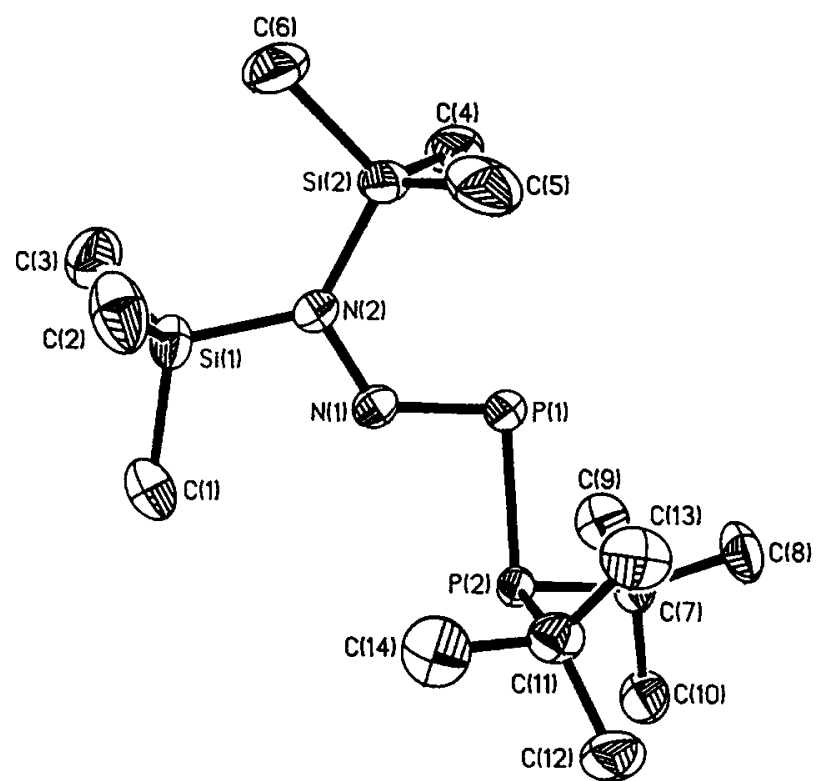

FIGURE 1 Structure of $\mathrm{BBu}_{2} \mathrm{P}-\mathrm{P}=\mathrm{N}-\mathrm{NR}_{2}\left(\mathrm{R}=\mathrm{SiMe}_{3}\right)$ (3) showing the atom numbering scheme.

$\mathrm{mL}$ of $\mathrm{Et}_{2} \mathrm{O}$. The reaction mixture was stirred until room temperature was achieved, whereby the $\mathrm{LiCl}$ precipitated. After filtration and evaporation of the solvent, the residue was purified by crystallization from pentane. Yield $5.8 \mathrm{~g}(89 \%)$ m.p. $146-149^{\circ} \mathrm{C}$.

${ }^{31} \mathrm{P}$ NMR $\left(\mathrm{C}_{6} \mathrm{H}_{6}\right) \delta=165.2,44.0\left(\mathrm{~J}_{\mathrm{PP}} 386 \mathrm{~Hz}\right) ;{ }^{1} \mathrm{H}$ $\operatorname{NMR}\left(\mathrm{C}_{6} \mathrm{H}_{6}\right) \delta=0.33,0.42,1.37\left(\mathrm{~J}_{\mathrm{PH}} 11.4 \mathrm{~Hz}\right), 1.55$ $\left(\mathrm{J}_{\mathrm{PH}} 12.6 \mathrm{~Hz}\right) ; \mathrm{m} / \mathrm{z} 423\left(\mathrm{M}-\mathrm{Cl}^{+}, 0.3 \%\right), 313$ $\left(\mathrm{Tms}_{3} \mathrm{~N}_{2} \mathrm{PCl}^{+}, 75 \%\right), 205\left(\mathrm{Tms}_{2} \mathrm{~N}_{2} \mathrm{P}^{+}, 35 \%\right), 145$ $\left(\mathrm{Bu}_{2}^{\mathrm{t}} \mathrm{P}^{+}, 8 \%\right), 73\left(\mathrm{Tms}^{+}, 100 \%\right)$.

\section{Preparation of $t B u_{2} P-P=N-N R_{2}$ (3)}

A solution of $4.0 \mathrm{~g}(8.7 \mathrm{mmol})$ of 2 and $6.7 \mathrm{~g} \mathrm{(44}$ $\mathrm{mmol}$ ) of DBU in $100 \mathrm{ml}$ of ether was stirred at $25^{\circ} \mathrm{C}$ for 5 days. The reaction mixture was filtered and the solvent evaporated under vacuum. Excess of DBU was removed under oil pump vacuum at $40^{\circ} \mathrm{C}$.

TABLE 1 Ab initio calculations on substituted iminophosphanes (trans-conformations), amino group in conjugation with the PN double bond

\begin{tabular}{llccc}
\hline$R^{\prime}$ & $R^{2}$ & $P N[\mathrm{pm}]$ & $<R^{1} P N\left[^{\circ}\right]$ & $<R^{2} N P\left[{ }^{\circ}\right]$ \\
\hline $\mathrm{H}$ & $\mathrm{H}$ & 154.8 & & 112.3 \\
$\mathrm{H}$ & $\mathrm{NH}_{2}$ & 158.6 & 100.0 & 123.7 \\
$\mathrm{H}_{2} \mathrm{P}$ & $\mathrm{H}$ & 154.7 & 101.1 & 112.7 \\
$\mathrm{H}_{2} \mathrm{P}^{a}$ & $\mathrm{NH}_{2}$ & 159.4 & 100.5 & 124.2 \\
\multicolumn{2}{l}{ a Bisected. } & & & \\
\hline
\end{tabular}

Low temperature crystallization from a little pentane gave pure 3. Yield $1.05 \mathrm{~g}(35 \%)$ m.p. $34-36^{\circ} \mathrm{C}$. ${ }^{31} \mathrm{P}$ NMR $\left(\mathrm{C}_{6} \mathrm{D}_{6}\right) \delta=428.7,53.0\left(\mathrm{~J}_{\mathrm{PP}} 266 \mathrm{~Hz}\right) ;{ }^{13} \mathrm{C}$ $\operatorname{NMR}\left(\mathrm{C}_{6} \mathrm{D}_{6}\right) \delta=1.05\left(\mathrm{~J}_{\mathrm{CP}} 5.9 \mathrm{~Hz}\right), 33.88\left(\mathrm{~J}_{\mathrm{CP}} 5.1 \mathrm{~Hz}\right.$, $13.2 \mathrm{~Hz}), 34.05\left(\mathrm{~J}_{\mathrm{CP}} 2.9 \mathrm{~Hz}, 30.8 \mathrm{~Hz}\right) ;{ }^{1} \mathrm{H}$ NMR $\left(\mathrm{C}_{6} \mathrm{D}_{6}\right)$ $\delta=0.37,1.44\left(\mathrm{~J}_{\mathrm{HP}} 10.8 \mathrm{~Hz}\right) ; \mathrm{m} / \mathrm{z} 350\left(\mathrm{M}^{+}, 0.3 \%\right), 236$ $\left(\mathrm{M}-2 \mathrm{Bu}^{\mathrm{t}+}, 2.5 \%\right), 205\left(\mathrm{Tms}_{2} \mathrm{~N}_{2} \mathrm{P}^{+}, 14 \%\right), 174$ $\left(\mathrm{Tms}_{2} \mathrm{~N}_{2}^{+}, 20 \%\right), 73\left(\mathrm{Tms}^{+}, 99 \%\right), 57\left(\mathrm{Bu}^{\mathrm{t}}, 100 \%\right)$.

\section{X-RAY STRUCTURE DETERMINATION}

Crystals of 3 were obtained by low temperature crystallization from a little pentane. The data were collected at $-85^{\circ} \mathrm{C}$ on a Stoe-Siemens AED diffractometer [H-profile fitting mode, Mo-K $\alpha$ radiation, $\lambda$ $=0.71072(\AA)]$, and solved and refined with SHELXS- and SHELX-76 respectively. The compound, $\mathrm{C}_{14} \mathrm{H}_{36} \mathrm{~N}_{2} \mathrm{P}_{2} \mathrm{Si}_{2}, \mathrm{M}_{\mathrm{r}}=350.57$ crystallizes in space group $\mathrm{P} 2_{1}, \mathrm{a}=7.203(1), \mathrm{b}=16.538(3), \mathrm{c}=$ $9.240(3), \alpha=90^{\circ}, \beta=91.70(2)^{\circ}, \gamma=90^{\circ}, \mathrm{V}=1.100$ $\mathrm{nm}^{3} ; \mathrm{Z}=2 ; \mathrm{D}_{\mathrm{c}}=1.06 \mathrm{~g} \mathrm{~cm}^{-3}$. A total of 2878 unique reflections were recorded of which 169 were considered as unobserved [ $F<4 \sigma(F)]$, leaving 2709 for solution and refinement. The final residuals were $R$ $=0.029$ and $R_{w}=0.030$. The structure was solved by direct methods. All non-hydrogen atoms were refined anisotropically. Hydrogen atoms were localized by difference electron-density determinations. The hydrogen atoms were refined using a "riding" model.

Atomic coordinates and selected bond lengths and angles are given in Tables 2 and 3. Additional

TABLE 2 Atomic coordinates $\left(\times 10^{4}\right)$ and equivalent isotropic displacement coefficients $\left(A^{2} \times 10^{3}\right)$ for unsolvated 3

\begin{tabular}{lrrrr}
\hline & $x$ & $y$ & \multicolumn{1}{c}{$z$} & $U($ eq) \\
\hline$P(1)$ & $2984(1)$ & 0 & $1776(1)$ & $32(1)$ \\
$P(2)$ & $3893(1)$ & $-53(1)$ & $4069(1)$ & $26(1)$ \\
$N(1)$ & $2253(3)$ & $925(1)$ & $1821(2)$ & $29(1)$ \\
$N(2)$ & $1574(3)$ & $1344(1)$ & $625(2)$ & $32(1)$ \\
$\mathrm{Si}(1)$ & $943(1)$ & $2342(1)$ & $1130(1)$ & $36(1)$ \\
$\mathrm{Si}(2)$ & $1700(1)$ & $937(1)$ & $-1144(1)$ & $39(1)$ \\
$\mathrm{C}(1)$ & $1136(4)$ & $2440(2)$ & $3116(3)$ & $47(1)$ \\
$C(2)$ & $2559(5)$ & $3072(2)$ & $308(4)$ & $63(1)$ \\
$C(3)$ & $-1498(4)$ & $2538(2)$ & $507(3)$ & $61(1)$ \\
$C(4)$ & $296(5)$ & $5(2)$ & $-1304(3)$ & $61(1)$ \\
$C(5)$ & $4169(5)$ & $774(3)$ & $-1557(3)$ & $71(1)$ \\
$C(6)$ & $722(5)$ & $1676(2)$ & $-2470(3)$ & $64(1)$ \\
$C(7)$ & $3793(4)$ & $-1188(2)$ & $4352(3)$ & $34(1)$ \\
$C(8)$ & $5109(5)$ & $-1701(2)$ & $3471(3)$ & $51(1)$ \\
$C(9)$ & $1801(4)$ & $-1426(2)$ & $3972(3)$ & $50(1)$ \\
$C(10)$ & $4128(5)$ & $-1355(2)$ & $5971(3)$ & $51(1)$ \\
$C(11)$ & $6397(4)$ & $300(2)$ & $3921(3)$ & $39(1)$ \\
$C(12)$ & $7547(4)$ & $22(2)$ & $5242(3)$ & $53(1)$ \\
$C(13)$ & $7390(4)$ & $61(2)$ & $2545(3)$ & $54(1)$ \\
$C(14)$ & $6221(4)$ & $1227(2)$ & $3971(4)$ & $58(1)$ \\
\hline
\end{tabular}


TABLE 3 Important bond lengths (pm) and angles (degrees)

\begin{tabular}{lllr}
\hline$P(1)-N(1)$ & $161.9(2)$ & $P(1)-N(1)-N(2)$ & $124.1(2)$ \\
$P(1)-P(2)$ & $220.1(1)$ & $N(1)-P(1)-P(2)$ & $95.8(1)$ \\
$N(1)-N(2)$ & $138.1(3)$ & $N(1)-N(2)-S i(1)$ & $110.0(1)$ \\
$N(2)-S i(1)$ & $177.8(2)$ & $N(1)-N(2)-S i(2)$ & $121.4(2)$ \\
$N(2)-S i(2)$ & $177.2(2)$ & $S i(1)-N(2)-S i(2)$ & $127.9(1)$ \\
$P(2)-C(7)$ & $189.6(3)$ & $P(1)-P(2)-C(7)$ & $99.3(1)$ \\
$P(2)-C(11)$ & $190.5(3)$ & $P(1)-P(2)-C(11)$ & $100.0(1)$ \\
& & $C(7)-P(2)-C(11)$ & $110.7(1)$ \\
$P(2)-P(1)-N(1)-N(2)$ & $176.3(2)$ & \\
$P(1)-N(1)-N(2)-S i(1)$ & $-179.4(1)$ & \\
$P(1)-N(1)-N(2)-S i(2)$ & $-7.7(3)$ \\
$N(1)-P(1)-P(2)-C(7)$ & $156.7(1)$ & \\
$N(1)-P(1)-P(2)-C(11)$ & $-90.2(1)$ & \\
\hline
\end{tabular}

material is available from the Cambridge Crystallographic Data Centre.

\section{Acknowledgement}

This work was supported by the Deutsche Forschungsgemeinschaft and the Fonds der Chemischen Industrie.

\section{References and Notes}

[1] (a) T. Busch, W. W. Schoeller, E. Niecke, M. Nieger, H. Westermann, Inorg. Chem., in press; W. W. Schoeller, in Multiple Bonding and Low Coordination in Phosphorus Chemistry, M. Regitz and O. J. Scherer (eds), Thieme Verlag, in press. (b) W. W. Schoeller, T. Busch, E. Niecke, J. Chem. Soc., Chem. Commun., submitted.

[2] E. Niecke, M. Nieger, F. Reichert, W. W. Schoeller, Angew. Chem. Int. Ed. Engl. 27, 1988, 1713; E. Niecke, M. Nieger, F. Reichert, Angew. Chem. Int. Ed. Engl. 27, 1988, 1715; L. N. Markovskii, V. D. Romanenko, V. D. Ruban, A. B. Drapailo, A. N. Chernaga, M. Yu. Antipin, Yu. T. Struchkov, Zh Obshch. Khim., 58, 1988, 291.

[3] E. Niecke, O. Altmeyer, M. Nieger, Angew. Chem. Int. Ed. Engl. 26, 1987, 1256.

[4] G. Becker, O. Mundt, M. Rössler, E. Schneider, Z. Anorg. Allg. Chem. 443, 1978, 42.

[5] U. Dressler, E. Niecke, S. Pohl, W. Saak, H.-G. Schäfer, W. W. Schoeller, J. Chem. Soc. Chem. Commun., 1986, 1086.

[6] E. Niecke, in Multiple Bonding and Low Coordination in Phosphorus Chemistry, M. Regitz and O. J. Scherer (eds), Thieme Verlag, in press.

[7] A. H. Cowley, R. A. Kemp, Chem. Rev., 1985, 367.

[8] The following Huzinaga basis sets were used [8a]: $\mathrm{P}\left[(4,6 \times 1 / 3,3 \times 1 /]\left(\zeta_{\mathrm{d}}=0.5\right), \mathrm{N}[5,3 \times 1 / 3,1 / 1]\left(\zeta_{\mathrm{d}}=\right.\right.$ $0.95) ; \mathrm{H}[3,1]$. Geometry optimizations were performed with the Karlsruhe version of Columbus package program [8b]. The search program was written by one of us [8c]. The accuracy of optimization is $10^{-8}$ a.u. in energy. Concomitantly the accuracy of bond lengths is $0.1 \mathrm{pmm}$.

[8a] S. Huzinaga, Approximate Atomic Functions. II, Technical Report, The University of Alberta, Edmonton, Alberta, Canada, 1971.

[8b] R. Ahlrichs, H. J. Böhm, C. Ehrhardt, P. Scharf, H. Schiffer, H. Lischka, M. Schindler, J. Comput. Chem. $6,1985,200$.

[8c] T. Busch, unpublished results.

[9] For a rationalization of the factors which influence the rotational barriers of the amino group, see: W. W. Schoeller, V. Staemmler, Inorg. Chem. 23, 1984, 3369. 